\title{
Influence of Alumina Nanoparticles on the Mechanical Properties of a Bioresin Composite
}

\author{
ION CIUCA ${ }^{1}$, OLEG SOLOMON ${ }^{2}$, CAMELIA ANA GRIGORE ${ }^{3}$, LUCRETIA ANGHEL ${ }^{3}$, \\ IULIAN CONSTANTIN ${ }^{3}$, MAGDA -ECATERINA ANTOHE ${ }^{4}$, ADRIAN BEZNEA ${ }^{3}$, \\ VALERIU ROMULUS HARABOR ${ }^{3}$, RAMONA FEIER ${ }^{5 *}$, SILVIA FOTEA ${ }^{3}$, GABI TOPOR ${ }^{3}$ \\ ${ }^{1}$ University Politehnica of Bucharest, 313 Splaiul Independentei, 060042, Bucharest, Romania \\ ${ }^{2}$ State University of Medicine and Pharmacy "Nicolae Testemitanu", Faculty of Dentistry, Chisinau, Republic of Moldova \\ 3"Dunărea de Jos" University of Galati, Faculty of Medicine and Pharmacy, 800201 Galati, Romania \\ 4"'Grigore T. Popa" University of Medicine and Pharmacy, Faculty of Dental Medecine, 16 Universitatii Str., 700115, Iasi, \\ Romania \\ 5“"Dimitrie Cantemir" University, Dental Medicine Schedule, 3-5 Bodoni Sandor Str, 540099, Targu-Mures, Romania
}

\begin{abstract}
A significant part of the research and production activities is represented in the field of bioengineering by the biomaterials used in hard tissue restorations. They are of great interest in dental science, intending to improve technological aspects, monitoring their biological responses to the living organisms, but also to redesign economic aspects, beginning with the choice of raw materials. In the present work, light-curing composite biomaterials were made from a composite polymer matrix consisting of specific concentrations of bisphenol A-glycidyl methacrylate base monomer (Bis-GMA), a mixture of two co-monomers, triethylene glycol dimethacrylate and ethoxylated bisphenol Adimethacrylate (TEGDMA/BisEMA), and two alumina nanopowder concentrations (5 wt.\% and 10 wt.\%). These materials were mechanically tested for flexural strength and compressive strength. The structural analysis of these materials consisted of SEM microscopy and EDX elementary mapping. In order to extract 3D projections of sample surfaces, but also to produce indicative values of their roughness, the SEM micrographs were processed with open-source software. In order to observe a clear evolution of the mentioned properties, the composite biomaterials were compared with materials formed only with the Bis-GMA/TEGDMA/BisEMA composite, and with a commercial composite resin, Filtek ${ }^{\mathrm{TM}}$ Supreme Ultra Universal Restorative, also. The findings showed an increase in the mechanical properties of the materials manufactured concerning the concentration of nanoparticles of aluminum. EDX analyzes confirmed the good homogeneity of nanoparticles in the polymer matrix. Mechanical properties of the manufactured nanocomposite biomaterials were reported $28.8 \%$ higher than the control biomaterial. The comparison results with the commercial resin composite are encouraging.
\end{abstract}

Keywords: biomaterials, alumina, Bis-GMA/TEGDMA/BisEMA resin composite, mechanical testing

\section{Introduction}

Biomaterials are advanced materials, created to be used as a biocompatible interface with the human body, in the form of medical devices, implants and prosthetic systems [1], without being rejected by the human body [2-5].

The dental materials used in dentistry are varied, with different compositions, indicated depending on the therapy to be followed. Among the most notable biomaterials are synthetic, organic or inorganic, namely polymeric [6] and ceramic [7,8]. Of course, these two types can be combined to form composite biomaterials.

The idea of using resins in dental implantology is at a mature stage, with good potential in making products, such as prosthesis bases, artificial teeth, temporary prostheses, gutters, sealants, etc., due to the satisfactory properties of abrasion resistance, light polishing, minimum shrinkage $[9,10]$ and compatibility with the tissues on which it aggregates [11]. 
Although they do not have the strength and aesthetics of porcelain restorations, they add to the financial aspect, being a cheap variant of a prosthesis. Examples of resins used in the dental field, both in research and production, are epoxy [12], urethane-dimethacrylate (UDMA) [13], bisphenol Aglycidyl methacrylate (Bis-GMA) [14], triethylene glycol dimethacrylate (TEGDMA) [15], to name a few. A breakthrough was the discovery of composite resins [16]. Currently, on the market, there are combinations of additive resins with inorganic matter (microparticles, nanoparticles), such as Filtek ${ }^{\mathrm{TM}}$ Supreme Ultra Universal Restorative (3M Oral Care), Vertise Flow (Kerr Corporation), Beautifil II (Shofu, Inc.), etc. Composite resins contain particles or hybrids of nano/microparticles in the filler that give properties in the working phase but also superior functional characteristics [9]. The majority of these additives are ceramics.

Ceramics are often used in dental applications and are experienced in bone tissue engineering applications [17]. An example of a common ceramic for dental applications is alumina [18].

Polycrystalline alumina $\left(\mathrm{Al}_{2} \mathrm{O}_{3}\right)$ has been used in biomaterials for more than 20 years [7] and is recognized as an inert material [8]. Due to the excellent resistance of alumina to corrosion, mechanical testing and wear, as well as good biocompatibility [19], this type of ceramic was the choice of this paper, is used in the form of nanoparticles.

In bioengineering, the use of nanoparticles in common products has been studied for almost 30 years [9], proving an excellent potential in covering gaps in research into new materials for dental reconstructions. Nano-additives, in particulate form, are incorporated into composite dental resins to provide restorative properties closely identical to a natural tooth, such as strength, appearance and adherence, also [11].

During the study of the effect of alumina nanoparticles on Bis-GMA/TEGDMA/BisEMA properties, the authors chose to opt for the use of two concentrations, $5 \mathrm{wt} . \%$ and $10 \mathrm{wt} \%$. The nano-composite resins were compared both with each other and with a control resin (pristine) and a commercial one.

After these nanoparticles have been incorporated into the polymeric matrix, the objective of this paper was to observe differences in the characteristics and mechanical properties of the potential dental reconstruction material. It is accepted globally that the longevity of dental restoration depends on the mechanical properties of the composite resins [20].

The novel aspects of the present study aim at customizing the structure of composite materials commonly used in dentistry by introducing alumina nanoparticles, comparing the results obtained with a representative composite material with wide use in practice, the concept of structural modifications being in full agreement with the particularities of masticatory forces, in conjunction with the location of the dental restoration, in order to achieve the aesthetic-functional balance.

The influence of pure alumina on the general properties of the proposed resin system, more specifically the mechanical properties, has not yet been discussed, from the knowledge of the authors.

\section{Materials and methods}

\subsection{Materials}

All materials were used as received, without further purification. As the base monomer of the resin matrix, bisphenol Aglycidyl methacrylate (Bis-GMA, C29H36O8, molecular weight $=512 \mathrm{~g} \cdot \mathrm{mol}^{-1}$ ) was used. The co-monomers of choice were triethylene glycol dimethacrylate (TEGDMA, C14H22O6, molecular weight $\left.=286 \mathrm{~g} \cdot \mathrm{mol}^{-1}\right)$ and ethoxylated bisphenol-A dimethacrylate $($ BisEMA, C39H44O8, molecular weight $=468 \mathrm{~g} \cdot \mathrm{mol}^{-1}$ ) and used in equal parts. To increase photopolymerization of the resins, very low concentrations ( 0.2 wt. $\%)$ of camphorquinone, as a photosensitizer, and ethyl 2,4dimethylbenzoate, were used. These materials were purchased from Sigma Aldrich. The alumina nanoparticles $\left(\alpha-\mathrm{Al}_{2} \mathrm{O}_{3}, 99.99 \%\right.$ purity, $30 \mathrm{~nm}$, MSE Supplies) were received in nanopowder form. Filtek $^{\mathrm{TM}}$ Supreme Ultra Universal Restorative (3M Oral Care) [21] was purchased as a modern commercial biocomposite and used as a comparison to the materials produced. 


\subsection{Manufacturing of biomaterials}

All materials were mechanically mixed for 24 hours in an enclosure isolated from any type of light source and stored for 48 hours at room temperature under the same conditions before being used. This method allows the gas particles to exit the viscous solutions that have taken place during the mixing process. Light-curing procedures were similar to all specimens with the help of a LED (light-emitting diode) poly wave transmission curing device (Bluephase Style, Ivoclar Vivadent AG) in single exposure for $60 \mathrm{~s}$ at their center.

A total of five samples were prepared for each type of analysis of the resin composite systems tested. Using an ultrasonic bath, the samples were cleaned for 5 minutes and stored in distilled water at $37{ }^{\circ} \mathrm{C}$ for $48 \mathrm{~h}$ until testing. Using a microscope slide, the pre-composition was made by light pressing into specific moulds, the dimensions of the resulting resins varying according to the analysis. The codes for the manufactured materials, as well as details of the composition and dimensions of nanomaterials, are provided in Table 1.

Table 1. The obtained composite materials and the concentrations of alumina nanoparticles added to the pre-polymerized solution for the studies of this work

\begin{tabular}{|c|c|c|c|}
\hline Material code & Resin composition & Filler & $\begin{array}{c}\text { Filler concentration } \\
{[w t \%]}\end{array}$ \\
\hline M0 & $\begin{array}{c}\text { Bis-GMA, TEGDMA, } \\
\text { BisEMA, 50:25:25 }\end{array}$ & - & - \\
\hline M1 & $\begin{array}{c}\text { Bis-GMA, TEGDMA, } \\
\text { BisEMA, 50:25:25 }\end{array}$ & $\alpha-\mathrm{Al}_{2} \mathrm{O}_{3}, 30 \mathrm{~nm}$ & 5 \\
\hline M2 & $\begin{array}{c}\text { Bis-GMA, TEGDMA, } \\
\text { BisEMA, 50:25:25 }\end{array}$ & $\alpha-\mathrm{Al}_{2} \mathrm{O}_{3}, 30 \mathrm{~nm}$ & 10 \\
\hline $\begin{array}{l}\text { Filtek }^{\mathrm{TM}} \text { Supreme Ultra } \\
\text { Universal Restorative* }\end{array}$ & $\begin{array}{l}\text { Bis-GMA, UDMA, } \\
\text { TEGDMA, BisEMA }\end{array}$ & $\begin{array}{l}20 \mathrm{~nm} \text { silica/ } 4 \text { to } 11 \mathrm{~nm} \text { zirconia (non- } \\
\text { agglomerated/ non-aggregated), and } \\
\text { aggregated, } 20 \mathrm{~nm} \text { silica and } 4 \text { to } 11 \mathrm{~nm} \\
\text { zirconia particles }\end{array}$ & 72.5 \\
\hline
\end{tabular}

* Information reported by manufacturers

The decision to use the 50:25:25 ratios between the monomer and the two co-monomers was made after examining the experimental analysis results of Goncalves et al [15], where they reported that the best combination, from a mechanical point of view, is for the two co-monomers to be added to the mixture in equal quantities, the basic monomer representing the greater part of the material.

\subsection{Experimental procedures}

The materials were characterized using advanced analysis methods from a structural, chemical and mechanical point of view. A scanning electron microscopy SEM was used to analyze surface structures (Vega-3, Tescan). X-ray scattering (EDX) coupled with the SEM microscope was used to analyze the elemental mapping of the key elements.

$3 \mathrm{D}$ projections $(30 \times 30 \mu \mathrm{m})$ were created to better understand the topography of composite materials based on SEM surface images, which better highlight the differences in roughness [22]. These projections were possible with the ImageJ open-source software (Interactive 3D Surface Plot plug-in) which uses grey differences of the SEM images. Additionally, it was possible to determine exact roughness values with the aid of this software, but with the SurfCharJ plug-in. This is a good characterization method, at least when it's not possible to access an AFM equipment. Several SEM microscopes with software already equipped with this projection option [23] are available as well.

Using a Universal Instron test machine, the mechanical properties of the manufactured composite and nanocomposite resins were measured using ISO 604 [24] and ISO 4049 [25] standards. Compression tests were conducted on specimens using a cylindrical split Teflon mold with a diameter of $4 \mathrm{~mm}$ and a height of $8 \mathrm{~mm}$. Compression was applied at $0.25 \mathrm{~mm} \cdot \mathrm{min}^{-1}$ cross-head speed with a load of $50 \mathrm{kN}$ until material failure, extracting compressive strength [MPa] data from the test instrument's specialized software. A three-point bending test was used to determine the flexural strength [MPa], with a crosshead speed of $0.5 \mathrm{~mm} \cdot \mathrm{min}^{-1}$ and a span between supports of $6 \mathrm{~mm}$, until sample failure. The samples were manufactured using a different Teflon mould with a rectangular shape measuring $2 \mathrm{~mm}$ in height, $2 \mathrm{~mm}$ 
in width and $25 \mathrm{~mm}$ in length. After removing any remaining flash, the polymerized samples were stored in distilled water as discussed.

\section{Results and discussions}

In the scanning electron microscopy of the composites produced, as seen in Figure 1, the surface of the materials showed a homogeneous texture. In the case of nanocomposite resins modified by the blending of alumina nanoparticles, the presence of nodules is quite apparent, especially at higher concentrations. This is a visual indicator of the presence of nanoparticles in the polymer matrix.

In the case of the Filtek ${ }^{\mathrm{TM}}$ Supreme Ultra composite, the highest number of nanoparticles is visible on the surface. This is due to the fact that this material has the highest concentration of nanoparticles among all the composite resins studied, fact is proven by SEM images (Figure 1, Supreme Ultra) and by EDX mapping (Figure 3, Si element, (Supreme Ultra) and Zr element (Supreme Ultra)).

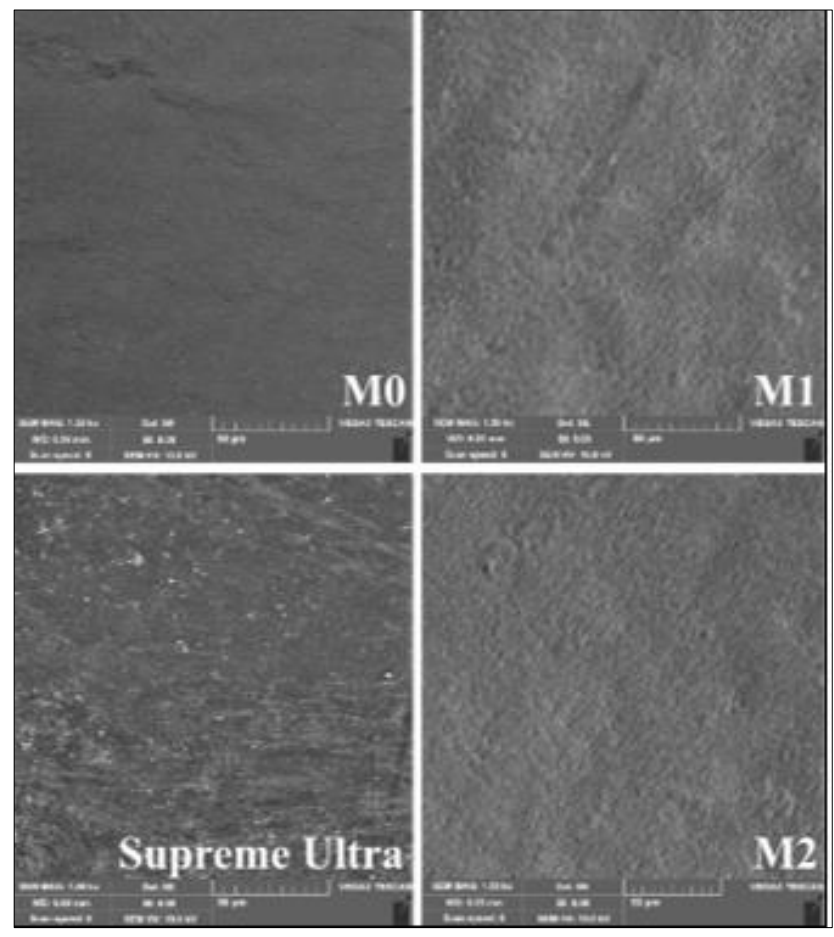

Figure 1. Scanning electron micrographs of the surfaces of the studied composite samples (magnification 1500x)

Visually, when analyzing the 3D images of the studied composites, it is shown a clear difference between samples. Commonly, all composites are passed through a finishing process to be in a polished state before characterization. Here, a direct study of roughness is not convenient, but mostly to demonstrate that all materials have similar luster [26]. Also, a lower roughness indicates a lower risk of bacterial accumulation inside the valleys of the materials [6].

Because the samples were not polished, the roughness analysis was significant from a contraction stress point of view of the resins at the time of polymerization [14]. Since nanoparticles do not have this attribute, resin monomers can shrink around them, resulting in nanoparticles being distinguished on composite surfaces, as observed in Figure 2. In the case of the control sample (M0, without nanoparticles), the roughness has the lowest value (Table 2), which is also rational since the contraction is uniform over the entire surface of the sample. In the case of $\mathrm{Al}_{2} \mathrm{O}_{3}$-modified bioresins ( $\mathrm{M} 1$ and $\mathrm{M} 2$ ), a higher concentration of nanoparticles can result in greater roughness values, achieving values comparable to those of commercial nanocomposite resins. 


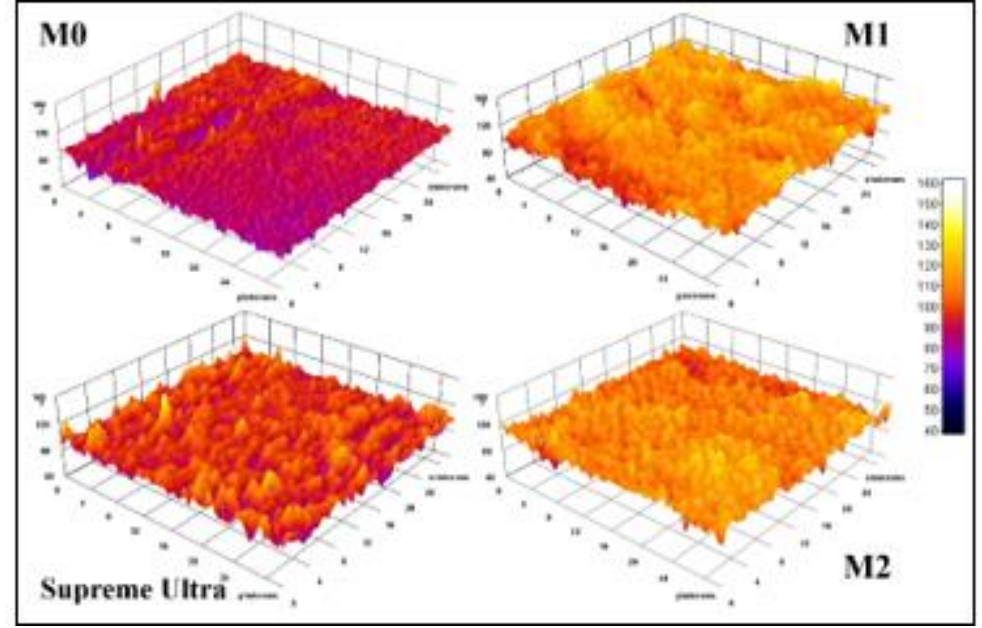

Figure 2. 3D representation based on the SEM surfaces of materials

EDX mapping is a good way to determine the homogeneity of the filler in a polymeric matrix [17]. All the composites showed a very good dispersion of nanoparticles in the material, as can be seen in Figure 3. For a large number of reasons, this aspect is very significant, particularly when the composite is under mechanical stress. In a filler-polymer chain bond, the formation of a good stress transfer can lead to higher mechanical resistance, and good homogeneity of the filler leads to a more uniform stress distribution.

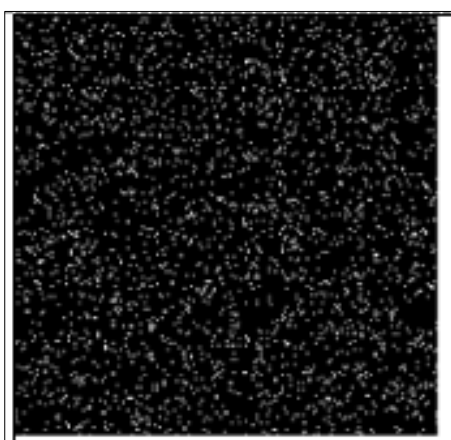

Si element (Supreme Ultra)

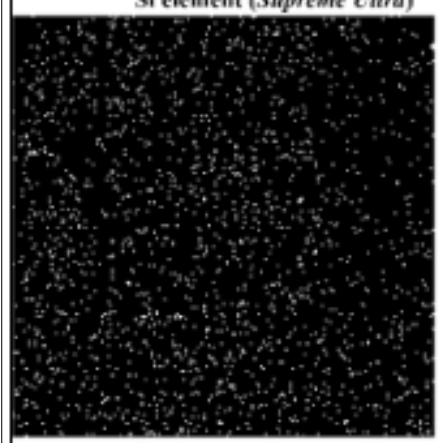

Zr elemeat (Supreme Ultra)
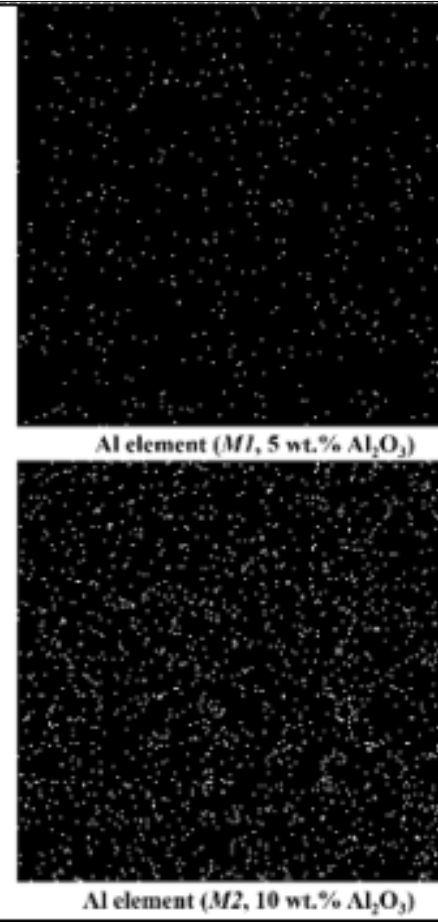

Figure 3. SEM-EDX maps for the Al element of the surface of composite materials containing $5 \mathrm{wt} . \%$ and 10 wt. $\% \mathrm{Al}_{2} \mathrm{O}_{3}$ nanoparticles, and maps for $\mathrm{Si}$ and $\mathrm{Zr}$ elements of the surface of Filtek $^{\text {TM }}$ Supreme Ultra composite material. Magnification 1500x

The means and standard deviations of the compressive test are shown in Table 2. It is seen that the compressive strength increases with the addition of nanoparticles into the composite resin, resulting in an increase of 28.8 percent compared to the control material. Flexural strength is consistent with the same trend, but with lower values. Mechanical control of nanocomposite resins is strongly related to the polymer chain-nanomaterial bond [27], which results in more uniform stress distribution and will minimize the occurrence of stress concentration, clearly leading to significant mechanical properties optimization of the resulting composites. Also, the uniform dispersions of the nanomaterials in the resin 
matrix enhanced the mechanical properties. Although for this study the amount of alumina nanoparticles was not high, mechanical properties were significantly improved.

The logic for which the compressive strength is higher than the flexural strength is that the nanoparticles are pressed on top of each other, pushing the stress more efficiently between them and the polymer chains. In the case of flexural stresses, nanoparticles move away from each other leading to the moment when defects appear that gradually cause the material to collapse. A higher number of nanoparticles will produce stronger polymer chains, leading to delays in the appearance of microcracks, confirming that materials with high filler content have more favorable mechanical properties.

Table 2. Mechanical tests and surface roughness analysis of materials.

\begin{tabular}{|c|c|c|c|c|}
\hline Material & $\begin{array}{c}\text { Compressive Strength } \\
{[\mathbf{M P a}]}\end{array}$ & $\begin{array}{c}\text { Flexural Strength } \\
{[\mathbf{M P a}]}\end{array}$ & $\begin{array}{c}\text { Ra: roughness } \\
\text { arithmetical mean } \\
\text { deviation* }\end{array}$ & $\begin{array}{c}\text { Rq: roughness root mean } \\
\text { square deviation* }\end{array}$ \\
\hline M0 & $234.803 \pm 11.209$ & $100.177 \pm 13.584$ & $6.651 \pm 1.213$ & $8.897 \pm 0.975$ \\
\hline M1 & $268.874 \pm 15.667$ & $116.769 \pm 9.006$ & $13.193 \pm 2.478$ & $16.896 \pm 3.098$ \\
\hline M2 & $312.935 \pm 19.051$ & $140.698 \pm 22.121$ & $15.071 \pm 2.122$ & $19.438 \pm 3.617$ \\
\hline $\begin{array}{c}\text { Filtek } \\
\text { Ultra Supreme } \\
\text { Restorative* }\end{array}$ & $343.967 \pm 19.643$ & $159.281 \pm 18.136$ & $13.627 \pm 3.032$ & $19.768 \pm 2.581$ \\
\hline
\end{tabular}

*units are expressed in pixel intensity

Filtek ${ }^{\mathrm{TM}}$ composites have a better response to mechanical tests due to the more complex nano-hybrid silica and zirconia system, mainly based on a wide range of nanoscale dimensions. The higher discrepancy between the various types of nanoparticles and the monomer chains increases further the polymer strength [6].

\section{Conclusions}

Under the conditions of this study, between the two alumina concentrations, it can be concluded that increasing the concentration of nano-particles, up to $10 \mathrm{wt} \%$, is a better contributor to overall mechanical properties. Based on experimental learning from the commercial dental biorensin, Filtek ${ }^{\mathrm{TM}}$ Supreme Ultra Universal Restorative, the choice of nanoparticle size could represent an important factor in the bioresin manufacture, which can represent further investigations in the case of alumina effect on the mechanical properties of resins.

In the study of dental restoration materials, and not only chemical, physical and biological aspects, the mechanical behavior of these materials is also, to say the least, very important. Understanding the limits of composite or nanocomposite resin from a mechanical point of view, it is crucial to determine the period of active service.

The biocomposite materials obtained have good potential for their use in dental restoration work. However, research is needed to continue in order to observe the effects of these materials in different biological environments, in vitro and in vivo.

\section{References}

1.WILLIAMS, D. F., The Williams Dictionary of Biomaterials. Liverpool University Press 1999, Liverpool ISBN 0-85323-734-4.

2CRETAN, M., GRIGORAS, S., HANGANU, L., STAMATE, C., HANGANU, S. C., MUNTEANU, F. HEMA Based Copolimers as Future Materials in Intervertebral Disc Replacements. Mater. Plast., 45(1), 2008, 109-112.

3.PEZZOTTI, G. 13-Surface chemistry of bioceramics: The missing key. Bioceramics 2021, 297-324. 4.BALTATU, M. S., VIZUREANU, P., BALAN, T., LOHAN, M., TUGUI, C.A., Preliminary Tests for Ti-Mo-Zr-Ta Alloys as Potential Biomaterials. IOP Conference Series-Materials Science and Engineering 2018, 374, 012023. 
5.BALTATU, M. S., VIZUREANU, P., GEANTA, V., NEJNERU, C., TUGUI, C. A., FOCSANEANU, S. C. Obtaining and Mechanical Properties of Ti-Mo-Zr-Ta Alloys. IOP Conference Series-Materials Science and Engineering 2017, 209, 012019.

6.ABUELENAIN, D.A.; ABOU NEEL, E. A; AL-DHARRAB, A. Surface and Mechanical Properties of Different Dental Composites. Austin J Dent. 2015, 2(2), 1019.

7.KERN, M., STRUB, J.R., Bonding to alumina ceramic in restorative dentistry: clinical results over up to 5 years. J. of Dentistry 1998, 26(3), 245-249.

8.UDDUTTULA, A., ZHANG, J.V., PEI-GEN, R., Bioinert Ceramics for Biomedical Applications. Biomedical Sci and Tech Series 2019, Wiley/Scrivener.

9.SAUNDERS, S.A., Current practicality of nanotechnology in dentistry. Part 1: Focus on nanocomposite restoratives and biomimetics. Clin Cosmet Investig Dent. 2009, 1, 47-6.

10.THOMAIDIS, S., KAKABOURA, A., MUELLER, W.D., ZINELIS, S., Mechanical properties of contemporary composite resins and their interrelations. Dental Materials 2013, 29, 132-141.

11.MURARIU, A., DINU, C., AGOP FORNA, D., STEFANESCU, V., TOPOR, G., FORNA, N.C., FOTEA, S.; GURAU, G.; IORDACHE, C. Composite Resins - Multifunctional Restorative Material and Practical Approaches in Dental Field. Mater. Plast., 57(2), 2020, 276-284.

12.SZÁVA, D.T., BÖGÖZI, B., SZÁVA, I., TARCOLEA, M., COMANEANU, R.M., ORMENISAN, A., Plastic Materials Used in Experimental Investigations Regarding Dental Implants Biomechanics. Mater.Plast., 52(2), 2015, 221-224.

13.GAJEWSKI, V.E.S., PFEIFER, C.S., FRÓES-SALGADO, N.R.G., BOARO, L.C.C., BRAGA, R.R., Monomers Used in Resin Composites: Degree of Conversion, Mechanical Properties and Water Sorption/Solubility. Braz Dent Journal 2012, 23(5), 508-514.

14.DEWAELEA, M., TRUFFIER-BOUTRY, D., DEVAUX, J., LELOUP, G., Volume contraction in photocured dental resins: The shrinkage-conversion relationship revisited, Dental Materials 2006, 22, 359-365.

15.GONCALVES, F., KAWANO, Y., PFEIFER, C., STANSBURY, J., W, BRAGA, R.R., Influence of BisGMA, TEGDMA, and BisEMA contents on viscosity, conversion, and flexural strength of experimental resins and composites. Eur J Oral Sci 2009, 117, 442-446.

16.MOEZZYZADEH, M. Evaluation of the Compressive Strength of Hybrid and Nanocomposites. Journal Dental School 2012, 1, 24-29.

17.AL-SANABANI, F.A., MADFA, A.A., AL-QUDAIMI, N.H., Alumina ceramic for dental applications: A review article. American Journal of Materials Research 2014, 1(1), 26-34.

18.COJOCARU, I., MOLDOVAN, M., TRIF, M., PRODAN, D., POPESCU, G.L., CONSTANTINESCU I., Influence of Some Alumina and Titanium Nanoparticles on the Mechanical Properties of the Composites Based on Poly (methyl methacrylate), Mater.Plast., 46(4), 2009, 383-386. 19.AL-MOAMERI H.H., NAHI, Z.M., RZAIJ D.R., AL-SHARIFY NOOR T., A review on the biomedical applications of alumina. Journal of Eng and Sustainable Development 2020, 24(05), 28-30. 20.NICA, I., IOVAN, G.S., STOLERIU, C.A., GHIORGHE, G., PANCU, R., COMANECI, A.; Comparative Study Regarding the Compressive Strength of Different Composite Resins Used for Direct Restorations, Mater.Plast., 55(3), 2018, 447-453

21.***3M, Filtek ${ }^{\mathrm{TM}}$ Supreme Ultra Universal Restorative, Technical Product Profile,

https://multimedia.3m.com/mws/media/13630180/3m-filtek-supreme-ultra-universal-restorative-

technical-product-profile.pdf.

22.PINTILIE, S.C., TIRON, L.G., LAZAR, A.L., VLAD, M., BIRSAN, I.G., BALTA, S., The Influence of $\mathrm{ZnO} / \mathrm{TiO}_{2}$ Nanohybrid Blending on the Ultrafiltration Polysulfone Membranes, Mater. Plast., 55(1), 2018, 54-62.

23.FLOREA, C.D., MUNTEANU, C., CIMPOESU, N., SANDU, I.G., BACIU, C., BEJINARIU, C. Characterization of Advanced Ceramic Materials Thin Films Deposited on Fe-C Substrate. Rev.Chim., 68(11), 2017, 2582-2587.

24.***ISO 604:2002, Plastics - Determination of compressive properties. International Organization for Standardization.

25.***ISO 4049:2000, Polymer-based filling, restorative and luting materials. International Organization for Standardization. 
26.RUIVO, M.A., PACHECO, R.R., SEBOLD, M., GIANNINI, M., Surface roughness and filler particles characterization of resin based composites. Microsc Res Tech. 2019, 1-12.

27.SAVA, S.; MOLDOVAN, M.; SAROSI, C.; MESAROS, A.; DUDEA, D.; ALB, C. Effects of Graphene Addition on the Mechanical Properties of Composites for Dental Restoration. Mater.Plast. 52(1), 2015, 90-92.

$\overline{\text { Manuscript received: } 15.03 .2021}$ 